\title{
Objective Response to First-Line Treatment as a Predictor of Overall Survival in Metastatic Breast Cancer: A Retrospective Analysis from Two Centers over a 25-Year Period
}

\author{
Alexios Matikas Athanasios Kotsakis Maria Perraki Dora Hatzidaki \\ Konstantinos Kalbakis Emmanouil Kontopodis Michail Nikolaou \\ Vasilios Georgoulias \\ Hellenic Oncology Research Group, Athens, Greece
}

\author{
Keywords \\ Chemotherapy - Metastatic breast cancer - Objective \\ response · Survival · Treatment line
}

\begin{abstract}
Introduction: The purpose of this study was to study the efficacy of subsequent treatment lines for metastatic breast cancer (MBC), as well as the association between radiologic objective response rate (ORR) and overall survival (OS). Methods: In this retrospective study, consecutive patients treated for MBC in two centers in Greece from January 1, 1992, to December 31, 2016, were identified and clinicopathologic data regarding tumor characteristics and administered treatments were collected. The efficacy per treatment line in terms of ORR, progression-free survival (PFS) and OS, as well as the prognostic value of ORR at first line were investigated. Results: A total of 977 patients with $M B C$ were identified; 950 received any treatment. At first line, ORR was $43.5 \%$, PFS 11.4 months ( $95 \% \mathrm{Cl} 10.4-12.4)$, and median OS 52.4 months (95\% Cl 47.7-57.1). Lower ORR and shorter PFS were observed with each subsequent line. Median OS was significantly longer for patients that had an objective response at first line, 61.9 months $(95 \% \mathrm{Cl} 51.1-69.7)$ for responders versus 41.3 months $(95 \% \mathrm{Cl} 44.1-63.3)$ for nonresponders $(p<0.001)$. In multivariable analysis, failure to achieve an objective response was an independent predictor of poor survival (hazard ratio 1.70, 95\% Cl 1.34-2.15, $p<$ 0.001). Conclusion: Late treatment lines for MBC seem to
\end{abstract}

karger@karger.com www.karger.com/brc

Karger $\%$ GOPEN ACCESS (c) 2021 The Author(s)

Published by S. Karger AG, Basel

This is an Open Access article licensed under the Creative Common Attribution-NonCommercial-4.0 International License (CC BY-NC) (http://www.karger.com/Services/OpenAccessLicense), applicable to the online version of the article only. Usage and distribution for commercial purposes requires written permission. have limited efficacy, while response to first-line therapy is associated with long-term survival. The latter should be considered in the treatment strategy of patients with MBC.

(C) 2021 The Author(s).

Published by S. Karger AG, Basel

\section{Introduction}

Despite continuous advancements in the understanding of the biology of metastatic progression and its therapeutic implications, metastatic breast cancer (MBC) remains the leading cause of cancer-related death in women [1]. The introduction of effective targeted agents, such as inhibitors of cyclin dependent kinases 4 and 6 (CDK4/6i), and antibodies against the human epidermal growth factor receptor 2 (HER2) has led to unprecedented outcomes with reported median overall survival (OS) up to 5 years in certain patient subgroups $[2,3]$. However, patient selection in clinical trials might be one of the driving forces behind the reported outcomes [4], which are not replicated in population-based studies that demonstrate a much shorter and relatively stable OS during the past 30 years $[5,6]$. Another possible contributor to this lack of improvement in the real-world clinical setting is the decreased efficacy of subsequent chemotherapy lines [7], a fact that complicates the interpretation of this setting of studies conducted at an earlier stage.

On the other hand, prognostication in MBC is traditionally inaccurate and mostly limited to clinical factors, such 
as disease-free interval [8], estrogen receptor status [9], and performance status. Crucially, all these factors are assessed at baseline, and the prognostic information they provide is independent and unaffected by response to treatment, which could also provide additional dynamic and accurate prognostication since it also takes into account the inherent - but largely variable and unique for every patient - chemosensitivity and resistance to endocrine manipulation [10, 11]. However, the proper endpoint to determine response to treatment is ill-defined, since radiologic response, time to progression, time to deterioration of quality of life, and OS are all meaningful goals when managing MBC. Nevertheless, the fact that imaging is performed early and regularly during treatment [12] and that its assessment is based on well-established and reproducible criteria [13] makes it an attractive option for its evaluation as a long-term prognosticator even with modern therapies.

Considering the aforementioned points, we conducted a retrospective study of all patients treated for MBC in two centers during a 25 -year period in order to evaluate the efficacy of subsequent treatment lines and validate objective response to first-line therapy as a predictor of patient survival.

\section{Methods}

\section{Study Design and Endpoints}

This is a retrospective cohort study whose dual objective was to investigate (1) the efficacy of later treatment lines for $\mathrm{MBC}$ in terms of objective response rate (ORR), progression-free survival (PFS), and OS and (2) to evaluate the association between response to first-line therapy and long-term survival. This noninterventional retrospective study was approved by the responsible ethics committee (decision number 2019/151).

Within the scope of this study, ORR was defined as the proportion of patients achieving complete response (disappearance of all disease according to radiology) and partial response (PR; reduction in size of tumor lesions). Progressive disease (PD) was defined as an increase in tumor lesions or the appearance of new ones, while stable disease (SD) included cases not defined as either PR or PD. The assessment of radiologic response was performed by the treating physician according to local practice, which was largely consistent with the initial version (1.0) of the Response Evaluation Criteria In Solid Tumors [14]. For each treatment line, the best radiologic response was documented, regardless of when that was achieved. PFS was defined as the time from initiation of treatment until the time of documentation of disease progression or death, whichever occurred first. OS was defined as the time from diagnosis of MBC until the time of death from any cause or the date of last follow-up.

\section{Description of Data Source}

The study cohort has been previously described [6]. All patients treated for breast cancer (BC) at the University Hospital of Heraklion, Crete, Greece and the Metropolitan General Hospital, Athens, Greece regardless of stage were identified, from database inception (January 1, 1992) until December 31, 2016. Of the initially identified 2,495 patients with BC, 1,518 were excluded due to no evidence of metastatic disease (Fig. 1). The remaining 977 patients comprise the study population of the present analysis, with the sole

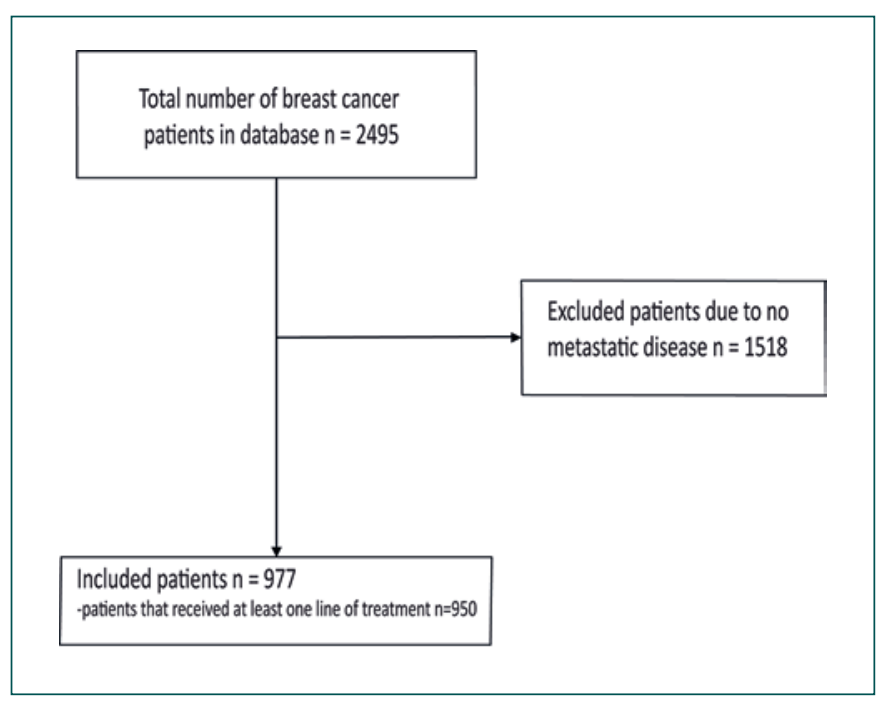

Fig. 1. Flowchart of data availability in the study.

eligibility criterion being the diagnosis of metastatic or locally advanced unresectable $\mathrm{BC}$, regardless of whether the patient received any oncologic treatment. Individual patient charts were assessed, and data were extracted regarding patient demographics (age at diagnosis, menopausal status), tumor pathologic characteristics (histologic type, hormonal receptor and HER2 expression at the primary tumor), and clinical information (date of diagnosis of metastatic disease, date of death). Information on all treatments received for both early and metastatic disease was also extracted and included type of regimens, date of initiation, date of termination, and best response assessed by imaging.

\section{Statistical Analysis}

The aim of this study was to describe both the real-world effectiveness of later treatment lines for $\mathrm{MBC}$ and the association between response to first-line therapy and long-term survival. Due to its descriptive nature, no formal statistical hypothesis was tested. Summary tables (descriptive statistics and/or frequency tables) were provided for all baseline and efficacy variables, as appropriate. Continuous variables were summarized with descriptive statistics ( $n$, median and range). Qualitative factors were compared by Pearson's $\chi^{2}$ test or Fisher's exact test whenever appropriate. Differences in continuous variables were assessed using the Mann-Whitney U test. Time-toendpoint events (PFS, OS) were estimated using the Kaplan-Meier method, and the comparisons were computed with the log-rank test. Logistic regression was performed in order to identify factors associated with the response to chemotherapy. The association between prognostic factors and survival was examined using Cox proportional hazards regression model. Spearman's rank correlation coefficient was used to evaluate the type of correlation between response and OS. An arbitrary level of 5\% statistical significance (two-tailed) was used. IBM SPSS Statistics version 22.0 (SPSS Inc., Chicago, IL, USA) was used to perform the statistical analyses.

\section{Results}

\section{Patient Characteristics}

The clinical and demographic characteristics of the patient cohort, as well as the median follow-up and OS for 
Table 1. Patient characteristics in the entire cohort, in patients that received at least one line of treatment, and in patients that received first-line chemotherapy versus endocrine therapy

\begin{tabular}{|c|c|c|c|c|c|}
\hline & $\begin{array}{l}\text { All patients } \\
(n=977)\end{array}$ & $\begin{array}{l}\text { Treated } \\
\text { patients } \\
(n=950)\end{array}$ & $\begin{array}{l}\text { Chemotherapy } \\
\text { at first line } \\
(n=710)\end{array}$ & $\begin{array}{l}\text { Endocrine at } \\
\text { first line } \\
(n=211)\end{array}$ & $\begin{array}{l}p \text { (chemotherapy } \\
\text { vs. endocrine) }\end{array}$ \\
\hline \multicolumn{6}{|l|}{ Age } \\
\hline Median (min.-max.) & $57(26-89)$ & $57(26-89)$ & $56(26-88)$ & $61(30-89)$ & \multirow{3}{*}{$\begin{array}{r}<0.001 \\
0.001\end{array}$} \\
\hline$\leq 60$ years & $578(59.2)$ & $563(59.3)$ & $437(61.5)$ & $104(49.3)$ & \\
\hline$>60$ years & $399(40.8)$ & $387(40.7)$ & $273(38.5)$ & $17(50.7)$ & \\
\hline \multicolumn{6}{|l|}{ Menopausal status } \\
\hline Premenopausal & $350(35.8)$ & $339(35.7)$ & $271(38.2)$ & $54(25.6)$ & \multirow{2}{*}{0.001} \\
\hline Postmenopausal & $627(64.2)$ & $611(64.3)$ & $439(61.8)$ & $157(74.4)$ & \\
\hline \multicolumn{6}{|c|}{ Status of disease at diagnosis } \\
\hline Local & $686(70.2)$ & $662(69.7)$ & $467(65.8)$ & $166(78.7)$ & \multirow{2}{*}{$<0.001$} \\
\hline Metastatic & $291(29.8)$ & $288(30.3)$ & $243(34.2)$ & $45(21.3)$ & \\
\hline \multicolumn{6}{|l|}{ Histology } \\
\hline Ductal & $763(78.1)$ & 740 (77.9) & $547(79.9)$ & $151(71.6)$ & \multirow{4}{*}{0.002} \\
\hline Lobular & $75(7.7)$ & $73(7.7)$ & $42(5.9)$ & $29(13.7)$ & \\
\hline Other & $50(5.1)$ & $49(5.1)$ & $36(5.1)$ & $11(5.2)$ & \\
\hline Not available & $89(9.1)$ & $88(9.3)$ & $65(9.2)$ & $20(9.5)$ & \\
\hline \multicolumn{6}{|l|}{ Estrogen receptor } \\
\hline Positive & $508(52.0)$ & $491(51.7)$ & $329(46.3)$ & $152(72.0)$ & \multirow{3}{*}{$<0.001$} \\
\hline Negative & $279(28.6)$ & $272(28.6)$ & $243(34.2)$ & $13(6.2)$ & \\
\hline Not available & $190(19.4)$ & $187(19.7)$ & $138(19.4)$ & $46(21.8)$ & \\
\hline \multicolumn{6}{|l|}{ Progesterone receptor } \\
\hline Positive & $416(42.6)$ & $404(42.5)$ & $270(38.0)$ & $124(58.8)$ & \multirow{3}{*}{$<0.001$} \\
\hline Negative & $363(37.2)$ & $352(37.1)$ & $295(41.5)$ & $41(19.4)$ & \\
\hline Not available & $198(20.3)$ & $194(20.4)$ & $145(20.4)$ & $46(21.8)$ & \\
\hline \multicolumn{6}{|l|}{ HER2 } \\
\hline Positive & $221(22.5)$ & $217(22.8)$ & $183(25.8)$ & $25(11.8)$ & \multirow{3}{*}{$<0.001$} \\
\hline Negative & $489(50.1)$ & $470(49.5)$ & $134(47.0)$ & $122(57.8)$ & \\
\hline Not available & $267(27.3)$ & $263(27.7)$ & $193(27.2)$ & $64(30.3)$ & \\
\hline
\end{tabular}

Values are $n(\%)$ unless otherwise indicated.

the entire cohort, have been previously presented [6]. Data availability is shown in Figure 1 and the clinicopathologic characteristics of the 950 patients that received at least one line of systemic treatment in relation to the entire cohort are described in Table 1. Patients were exposed to a minimum of 1 and a maximum of 10 treatment lines, with chemotherapy being the dominant choice (Table 2). Hormone receptor-positive patients were more likely to receive more than 5 treatment lines (odds ratio 1.92, 95\% confidence interval [CI] 1.17-3.13, $p=0.009$ ) in multivariable analysis when both chemotherapy and hormonal therapy were considered; no other factors independently predicted receipt of more than 5 treatment lines. The majority was treated with first-line chemotherapy, while $22 \%$ initiated treatment with endocrine therapy. The distribution of patient characteristics according to treatment is shown in Table 1.

\section{Patient Outcomes}

After a median follow-up of 52.0 months (95\% CI 47.4-57.1), the median PFS following first-line treatment was 11.4 months (95\% CI 10.4-12.4), and the median OS was 52.4 months (95\% CI 47.7-57.1); the corresponding probability for 1 -year survival was $88.1 \%$. Patients with hormone receptor-positive/HER2-negative BC had improved OS, 53.7 months (95\% CI 48.2-59.3) compared to 26.0 months (95\% CI 19.8-32.2) for triple negative ones $(p<0.001)$. Of note, both PFS (12.4 months, 95\% CI 10.314.5 , vs. 10.9 months, $95 \%$ CI $9.8-12.1 ; p=0.005)$ and OS (57.7 months, 95\% CI 50.2-65.2, vs. 47.9 months, 95\% CI $41.5-54.2 ; p=0.02$ ) were longer in patients that had single-organ involvement at baseline.

\section{Effect of Maintenance Therapy, HER2-Targeting Agents, and Subsequent Treatments on Patient Outcomes}

A total of 347 patients with hormone receptor-positive/HER2-negative MBC that were treated with first-line chemotherapy were identified, of which 122 received maintenance endocrine therapy following nonprogression to chemotherapy. Compared to those that did not receive maintenance endocrine therapy, patients on 
Table 2. Type of administered therapy and efficacy per treatment line

\begin{tabular}{|c|c|c|c|c|c|c|c|c|}
\hline & \multirow{2}{*}{$\begin{array}{l}\text { Patients, } \\
n\end{array}$} & \multicolumn{4}{|c|}{ Type of therapy, $n(\%)$} & \multicolumn{3}{|l|}{ Efficacy } \\
\hline & & Chemotherapy & $\begin{array}{l}\text { Endocrine } \\
\text { therapy }\end{array}$ & $\begin{array}{l}\text { Postoperative } \\
\text { therapy }\end{array}$ & Other & $\begin{array}{l}\text { ORR (CR + PR), } \\
\%\end{array}$ & $\begin{array}{l}\text { PFS }(95 \% \mathrm{Cl}) \text {, } \\
\text { months }\end{array}$ & $\begin{array}{l}\text { OS }(95 \% \mathrm{Cl}) \text {, } \\
\text { months }\end{array}$ \\
\hline \multicolumn{9}{|c|}{ Therapy line } \\
\hline First & 950 & $710(74.7)$ & $211(22.2)$ & $25(2.6)$ & $4(0.4)$ & 43.5 & $11.4(10.4-12.4)$ & $52.4(47.7-57.1)$ \\
\hline Second & 691 & $531(76.8)$ & $141(20.4)$ & $1(0.1)$ & $18(2.6)$ & 21.9 & $5.5(5.0-6.0)$ & $29.4(26.3-32.4)$ \\
\hline Third & 537 & $383(71.3)$ & $132(24.5)$ & & $22(4.1)$ & 14.4 & $5.1(4.5-5.7)$ & $24.1(21.3-26.9)$ \\
\hline Fourth & 388 & $295(75.6)$ & $77(19.8)$ & & $16(4.1)$ & 15.8 & $5.2(4.7-5.6)$ & $18.6(15.1-22.1)$ \\
\hline Fifth & 268 & $213(79.5)$ & $40(14.9)$ & & $15(5.6)$ & 13.1 & $4.6(4.0-5.2)$ & $15.0(10.0-20.0)$ \\
\hline Sixth & 173 & $133(76.9)$ & $27(15.7)$ & & $13(7.5)$ & 11.0 & $3.7(3.0-4.4)$ & $15.4(11.1-19.6)$ \\
\hline Seventh & 112 & $93(83.0)$ & $14(12.5)$ & & $5(4.5)$ & 7.1 & $3.1(2.0-4.2)$ & $14.8(13.0-16.5)$ \\
\hline Eighth & 68 & $55(80.9)$ & $12(17.6)$ & & $1(1.5)$ & 5.9 & $3.4(2.3-4.4)$ & $11.8(8.6-15.0)$ \\
\hline Ninth & 37 & $33(89.2)$ & $3(8.1)$ & & $1(2.7)$ & 5.4 & $2.8(2.0-3.6)$ & $9.9(3.7-16.1)$ \\
\hline Tenth & 22 & $16(72.7)$ & $6(27.3)$ & & - & 9.1 & $3.4(1.7-5.1)$ & $12.5(4.0-20.9)$ \\
\hline
\end{tabular}

$\mathrm{Cl}$, confidence interval; $\mathrm{CR}$, complete response; $\mathrm{ORR}$, objective response rate; OS, overall survival; PFS, progression-free survival; PR, partial response.

Table 3. Multivariable Cox regression analysis for overall survival in the 651 patients with available data

\begin{tabular}{|c|c|c|}
\hline & $\begin{array}{l}\text { Hazard ratio } \\
(95 \% \mathrm{Cl})\end{array}$ & $p$ value \\
\hline Hormone receptor status & & 0.019 \\
\hline At least one positive & 1 (reference) & \\
\hline Both negative & $1.38(1.05-1.80)$ & \\
\hline HER2 status & & 0.033 \\
\hline Positive & 1 (reference) & \\
\hline Negative & $1.33(1.02-1.72)$ & \\
\hline Age & & 0.121 \\
\hline$\leq 60$ years & $1.29(1.01-1.65)$ & \\
\hline$>60$ years & 1 (reference) & \\
\hline Visceral disease & & 0.076 \\
\hline Yes & $1.24(0.98-1.58)$ & \\
\hline No & 1 (reference) & \\
\hline Type of first-line therapy & & 0.631 \\
\hline Chemotherapy & 1 (reference) & \\
\hline Endocrine therapy & $1.08(0.79-1.47)$ & \\
\hline Objective response to first line & & $<0.001$ \\
\hline Complete or partial response & 1 (reference) & \\
\hline Stable or progressive disease & $1.70(1.34-2.15)$ & \\
\hline Disease-free interval & & 0.013 \\
\hline$\geq 36$ months or de novo metastatic & 1 (reference) & \\
\hline$<36$ months & $1.36(1.07-1.73)$ & \\
\hline
\end{tabular}

$\mathrm{Cl}$, confidence interval.

maintenance had improved PFS (25.9 months, 95\% CI 19.1-32.6, vs. 7.7 months, $95 \%$ CI $6.1-9.3 ; p<0.001)$ and OS (62.3 months, 95\% CI 52.3-76.2, vs. 46.6 months, $39.8-53.4 ; p<0.001)$.

There was considerable lack of reporting of HER2 status, especially in patients diagnosed prior to the publication of the initial trastuzumab trials. 105 of the $217 \mathrm{pa}$ tients with known HER2-positive disease received at some point at least one HER2-targeted agent, and these had a numerically, but not statistically significant, superior OS compared to HER2-positive patients that never received HER2 blockade (55.7 [41.0-70.3] vs. 48.2 [29.666.8] months; $p=0.664$ ).

Expectedly, probability for an objective response was lower and PFS was shorter with each successive therapy line, as shown in Table 2.

\section{Objective Response to First-Line Treatment Is a \\ Predictor of Long-Term Outcomes}

Out of the 950 patients that received at least one line of treatment, $70(7.4 \%)$ had a radiologically complete response and 343 patients had a PR (36.1\%) for an ORR to first-line treatment of $43.5 \%$ (95\% CI 40.3-46.6). In contrast, 273 patients $(28.7 \%)$ had SD as best response and 192 patients (20.2\%) had disease progression at first assessment. The remaining patients had either no evidence of disease (postoperative therapy, $n=34$ patients; $3.6 \%$ ) or no evaluable information ( $n=38$ patients; $4.0 \%)$. An objective response was achieved by $51.0 \%$ of patients treated with first-line chemotherapy compared to $32.2 \%$ of those treated with first-line endocrine therapy $(p<$ $0.001)$. However, rates of PD as best response on first-line treatment were similar between the two groups (24.0 vs. $23.6 \%$, respectively; $p=0.894$ ).

Responders at first line had improved PFS at first line (PFS1) compared to nonresponders (16.3 months, 95\% CI $14.3-18.3$, vs. 6.6 months, $95 \%$ CI $5.7-7.4 ; p<0.001$ ) but not at second line (PFS2; 6.0 months, 95\% CI 5.3-6.8, vs. 5.2 months, $95 \%$ CI $4.7-5.8 ; p=0.41$ ). At the time of data cutoff, 192 patients with an objective response at first line and 255 patients with SD or PD had died. Median OS was significantly longer for patients that had an objective response (hazard ratio [HR] 1.81, 95\% CI 1.50-2.2, $p<$ 


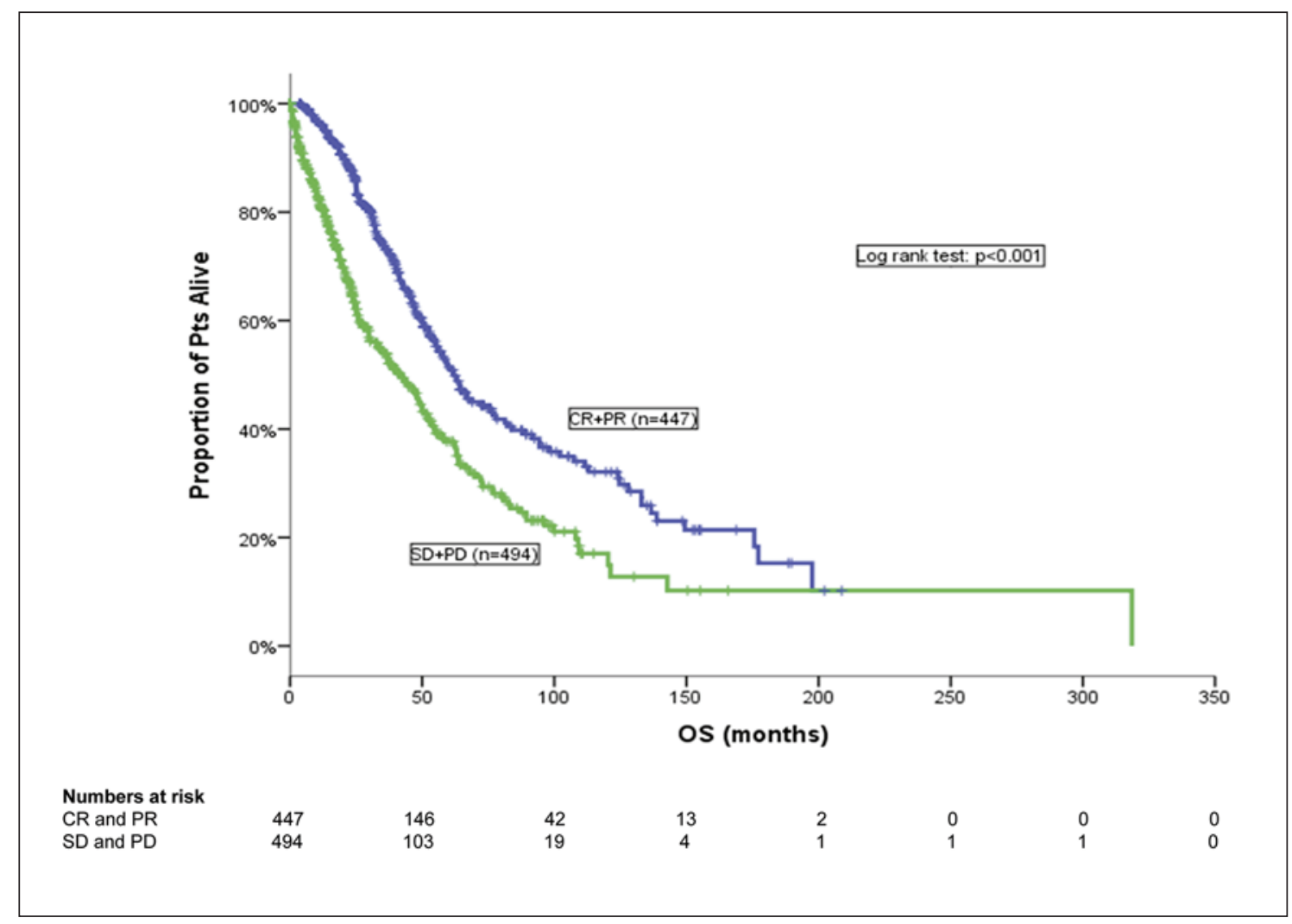

Fig. 2. Kaplan-Meier curve of OS for patients achieving an objective response to first-line treatment versus patients with SD or PD. CR, complete response; OS, overall survival; PD, progressive disease; PR, partial response; $\mathrm{SD}$, stable disease.

0.001); the corresponding median OS was 61.9 months (95\% CI 51.1-69.7) for responders versus 41.3 months (95\% CI 44.1-63.3) for nonresponders ( $p<0.001$; Fig. 2). In multivariable analysis, failure to achieve an objective response to first-line treatment was an independent predictor of poor survival outcome, when adjusted for ER status, HER2 status, age, site of metastasis, type of firstline therapy, and disease-free interval (HR 1.70, 95\% CI $1.34-2.15, p<0.001$; Table 3 ).

On the other hand, patients with SD as best response to first line had also improved OS compared to those that progressed directly on first line, 53.7 months (95\% CI 44.1-43.3) versus 19.5 months (95\% CI $14.6-24.4$; $p<$ 0.001 ). Further analysis showed that SD for 6 months or longer as best response was associated with improved OS compared to SD for a shorter period $(p<0.001)$, but not with improved ORR $(p=1.0)$ or PFS $(p=0.143)$ at the second line.

Patients with Short Survival Are Usually Nontreated, but Do Not Have More Biologically Aggressive Tumors Sixty-six patients with an OS of 3 months or shorter were identified in the cohort. Compared to the rest of the cohort, these patients were older (median age 65 vs. 57 years, $p<0.001)$ and more commonly did not receive any treatment for metastatic disease ( 31.8 vs. $0.7 \%$ of patients were untreated, $p<0.001$ ). However, receptor status (estrogen receptor, $p=0.92$; progesterone receptor, $p=0.64$; HER2, $p=0.73$ ), de novo metastatic disease (22.7 vs. $30.3 \%, p=0.19)$, prior adjuvant chemotherapy $(p=0.39)$ and endocrine therapy $(p=0.68)$, as well as the number of organs involved $(p=0.64)$, did not significantly differ between the two patient groups.

\section{Discussion}

In this retrospective analysis of patients treated for $\mathrm{MBC}$ in two centers within a long period of time we aimed to provide data on real-world efficacy of late-line treatment and to evaluate radiologic response to first line as a prognostic factor. Regarding the management of heavily pretreated patients, few prospective randomized data inform on whether to pursue further treatment beyond the third line, and decision-making is based on extrapolating data from first- and second-line trials. In our study, PFS following first- and second/third-line treatment was in line with that reported for chemotherapy for treatment- 
naïve [15] and pretreated patients [16, 17]. However, the efficacy of later lines of treatment is doubtful since no randomized trial has shown survival benefit from any cytotoxic agent following 4 or more chemotherapy lines for advanced disease $[16,18]$. This observation extends even to novel agents, such as immunotherapy by checkpoint inhibition and CDK4/6i, which exhibit markedly decreased efficacy in heavily pretreated patients $[19,20]$ compared to the results of trials at earlier stages of the MBC trajectory [21, 22]. Even in cases where novel targeted agents retain their efficacy in later lines, such as trastuzumab emtansine [23], their use is now transitioned to the second line [24] or even to the adjuvant setting [25], leaving few options for pretreated patients. In the present study, median PFS at each treatment line after the fifth was approximately 3 months, which corresponds to the time of first radiologic assessment after the initiation of a new treatment [12] and thus represents the change to another regimen at the first opportunity presumably due to disease progression. Although treatment allocation in this study was not randomized and the effect of treatment on OS cannot be assessed, not responding to prior treatment has been shown to be a negative predictive factor for following lines [26, 27], a fact which casts doubt on the current paradigm of continuous mono-chemotherapy until the patient is exposed to every available agent regardless of prior chemosensitivity.

In recent times, oncologic thought and treatment guidelines have put emphasis on achieving long periods of disease control while retaining quality of life $[12,28]$ and not on aggressively treating with combination chemotherapy, even though the latter has been shown to improve OS albeit at the cost of increased toxicity [29], but not when the same chemotherapy is given in succession [30]. Since radiologic response to initial treatment is easily assessed at a very early time point, starting therapy with the goal to attain an objective response, regardless of whether this is achieved with combination chemotherapy, monochemotherapy, or CDK4/6 inhibition, which increases ORR compared to endocrine therapy alone, and then de-escalate could represent a valid strategy - provided that this initial objective response is associated with improved survival. This has previously been the subject of several studies [31] and meta-analyses with partially conflicting results [32-34], not least due to the long natural history of $\mathrm{MBC}$, which dilutes treatment effects. The association between initial response and OS seems nevertheless to be consistent and even extends to micrometastatic disease [35], albeit not strong enough to warrant the use of ORR as a surrogate for the regulatory approval of new agents [34]. However, ORR may very well inform treatment strategies at the clinical setting: for example, in the present cohort of heavily pretreated patients (median 4 and maximum 10 lines for metastatic disease), response to first-line treatment was an independent predictor of outcomes. The potential importance of response to firstline therapy concerns not only chemotherapy, but endocrine monotherapy or combinations with molecularly targeted therapy as well, although our study was not powered to extend this observation to response according to therapy type.

The verisimilitude of this correlation is further bolstered by 5 additional observations in our study: (1) although first-line chemotherapy induced higher response rates, in multivariable analysis choice of therapy was not predictive of OS, which implies that an objective response is critical regardless of which modality is used to achieve it; (2) patients with short survival were largely untreated but did not have biologically more aggressive cancers, thus highlighting the importance of prompt initiation of effective treatment in patients fit enough to receive it; (3) the lack of benefit for first-line responders in terms of PFS at the second line, which indicates that the association between initial objective response and survival is not caused by a selection of patients inherently sensitive to endocrine manipulation or cytotoxicity; (4) the survival benefit for patients with prolonged SD, who also did not fare better at the second line than patients with short-lived disease control, and (5) the survival benefit with maintenance endocrine therapy which aims to extend first-line treatment for as long as possible, although it should be noted that maintenance therapy was not compared to treatment with the same agents in succession. Consequently, this study supports a treatment paradigm towards early aggressive treatment (though not necessarily with chemotherapy) in order to maximize both depth of response and number of responders followed by periods of maintenance therapy, especially when considering the decreased efficacy of subsequent treatment lines.

The present study was a retrospective survey of administered treatment to consecutive patients in a long period of time, which introduces selection bias since patients with impaired performance status or otherwise poor candidates for treatment were potentially excluded, beyond the small proportion of the cohort that were identified as untreated. In addition, treatment allocation was not randomized, which precludes definitive conclusions regarding our largely exploratory findings. Further possible sources of bias are the missing clinicopathologic information which did not allow for further analyses per BC subtype, the lack of central radiology review, the diversity of therapies used, and the fact that data collection was terminated at the end of 2016, therefore prior to the widespread introduction to clinical practice of CDK4/6i, which confer long-term control of hormone receptorpositive/HER2-negative disease. In addition, partially due to the time period of this analysis, many patients ei- 
ther had unknown HER2 status or received HER2-targeted therapies late during the disease trajectory, which confounds the interpretation of our results for this patient subgroup - especially considering the multiple randomized trials that have shown improved OS with HER2 blockade. Finally, aspects important in MBC, such as toxicity and quality of life, were not assessed in the study.

\section{Conclusions}

In this retrospective analysis, late treatment lines for $\mathrm{MBC}$ seemed to have limited efficacy, while response to first-line therapy was associated with long-term survival. The latter should be considered in the treatment strategy of patients with $\mathrm{MBC}$, although the conflicting nature of published analyses of data from prospective trials should be taken into consideration.

\section{Statement of Ethics}

All procedures performed in studies involving human participants were in accordance with the ethical standards of the institutional and/or national research committee and with the $1964 \mathrm{Hel}-$ sinki Declaration and its later amendments or comparable ethical standards. This is a noninterventional retrospective review of patient charts, approved by the responsible ethics committees at the University Hospital of Heraklion and Metropolitan Athens General Hospital (decision number 2019/151). No animal experiments were performed. No informed consent is needed according to the responsible ethics committee (decision number 2019/151).

\section{Conflict of Interest Statement}

Alexios Matikas, Maria Perraki, Dora Hatzidaki, Konstantinos Kalbakis, and Michail Nikolaou have no conflicts of interest to disclose. Emmanouil Kontopodis has received research grants from Amgen and Astellas, honoraria from Bristol Myers Squibb, Roche, Merck Sharp \& Dohme (MSD), and Angelini Pharma and travel grants from MSD, Aenorasis, and Genesis Pharma. Athanasios Kotsakis has received research grants and honoraria for participation in advisory boards from MSD, Roche, Bristol, and Astra Zeneca. Vasilios Georgoulias has received research grants and honoraria for participation in advisory boards from Amgen, Pfizer, Astra Zeneca, Roche, Sanofi-Aventis, and Novartis.

\section{Funding Sources}

Alexios Matikas is supported by the Stockholm Region (clinical postdoctorial appointment, dnr K 2017-4577). No other funding relevant for this study was received.

\section{Author Contributions}

Study conception: A.M., V.G. Data extraction: A.M., A.K., M.P., K.K., E.K., and M.N. Data analysis: D.H. Interpretation of results: A.M. and V.G. Initial draft: A.M. and D.H. Critical revisions: all authors.

\section{Data Availability Statement}

The dataset generated and analyzed during the current study is available from the corresponding author on reasonable request.

\section{References}

1 Siegel RL, Miller KD, Jemal A. Cancer statistics, 2020. CA Cancer J Clin. 2020 Jan;70(1): 7-30. http://dx.doi.org/10.3322/caac.21590.

2 Slamon DJ, Neven P, Chia S, Fasching PA, De Laurentiis M, Im SA, et al. Overall survival with ribociclib plus fulvestrant in advanced breast cancer. N Engl J Med. 2020 Feb;382(6): $514-24$.

3 Swain SM, Miles D, Kim SB, Im YH, Im SA, Semiglazov V, et al. Pertuzumab, trastuzum$\mathrm{ab}$, and docetaxel for HER2-positive metastatic breast cancer (CLEOPATRA): end-ofstudy results from a double-blind, randomised, placebo-controlled, phase 3 study. Lancet Oncol. 2020 Apr;21(4):519-530. http: //dx.doi.org/10.1016/S1470-2045(19)30863-

4 Booth CM, Tannock IF. Randomised controlled trials and population-based observational research: partners in the evolution of medical evidence. Br J Cancer. 2014 Feb; 110(3):551-5.

5 Foukakis T, Fornander T, Lekberg T, Hellborg $\mathrm{H}$, Adolfsson J, Bergh J. Age-specific trends of survival in metastatic breast cancer: 26 years longitudinal data from a populationbased cancer registry in Stockholm, Sweden.
Breast Cancer Res Treat. 2011 Nov;130(2): $553-60$.

6 Edman Kessler L, Sigfridsson J, Hatzidaki D, Bergh J, Foukakis T, Georgoulias V, et al. Chemotherapy use near the end-of-life in patients with metastatic breast cancer. Breast Cancer Res Treat. 2020;181(3):645-51.

7 Cardoso F, Di LA, Lohrisch C, Bernard C, Ferreira F, Piccart MJ. Second and subsequent lines of chemotherapy for metastatic breast cancer: what did we learn in the last two decades?. Ann Oncol. 2002 Feb;13(2): 197-207.

8 Yamamoto N, Watanabe T, Katsumata N, Omuro Y, Ando M, Fukuda H, et al. Construction and validation of a practical prognostic index for patients with metastatic breast cancer. J Clin Oncol. 1998 Jul;16(7): 2401-8.

9 Clark GM, Sledge GW Jr, Osborne CK, McGuire WL. Survival from first recurrence: relative importance of prognostic factors in 1,015 breast cancer patients. J Clin Oncol. 1987 Jan;5(1):55-61.

10 Matikas A, Foukakis T, Bergh J. Tackling endocrine resistance in ER-positive HER2-negative advanced breast cancer: A tale of impre- cision medicine. Crit Rev Oncol Hematol. 2017 Jun;114:91-101.

11 Foukakis T, Lövrot J, Matikas A, Zerdes I, Lorent J, Tobin N, et al. Immune gene expression and response to chemotherapy in advanced breast cancer. Br J Cancer. 2018 Feb; 118(4):480-8.

12 Cardoso F, Senkus E, Costa A, Papadopoulos E, Aapro M, André F, et al. 4th ESO-ESMO International Consensus Guidelines for Advanced Breast Cancer (ABC 4). Ann Oncol. 2018 Aug; 29(8): 1634-57. http://dx.doi. org/10.1093/annonc/mdy192.

13 Eisenhauer EA, Therasse P, Bogaerts J, Schwartz LH, Sargent D, Ford R, et al. New response evaluation criteria in solid tumours: revised RECIST guideline (version 1.1). Eur J Cancer. 2009 Jan;45(2):228-47.

14 Therasse P, Arbuck SG, Eisenhauer EA, Wanders J, Kaplan RS, Rubinstein L, et al. New guidelines to evaluate the response to treatment in solid tumors. European Organization for Research and Treatment of Cancer, National Cancer Institute of the United States, National Cancer Institute of Canada. J Natl Cancer Inst. 2000 Feb;92(3): 205-16. 
15 Rugo HS, Barry WT, Moreno-Aspitia A, Lyss AP, Cirrincione C, Leung E, et al. Randomized phase III trial of paclitaxel once per week compared with nanoparticle albumin-bound nab-paclitaxel once per week or ixabepilone with bevacizumab as first-line chemotherapy for locally recurrent or metastatic breast cancer: CALGB 40502/NCCTG N063H (Alliance). J Clin Oncol. 2015 Jul;33(21):2361-9.

16 Cortes J, O'Shaughnessy J, Loesch D, Blum JL Vahdat LT, Petrakova K, et al. Eribulin monotherapy versus treatment of physician's choice in patients with metastatic breast cancer (EMBRACE): a phase 3 open-label randomised study. Lancet. 2011 Mar;377(9769):914-23.

17 Kaufman PA, Awada A, Twelves C, Yelle L, Perez EA, Velikova G, et al. Phase III openlabel randomized study of eribulin mesylate versus capecitabine in patients with locally advanced or metastatic breast cancer previously treated with an anthracycline and a taxane. J Clin Oncol. 2015 Feb;33(6):594-601.

18 Perez EA, Awada A, O’Shaughnessy J, Rugo HS, Twelves C, Im SA, et al. Etirinotecan pegol (NKTR-102) versus treatment of physician's choice in women with advanced breast cancer previously treated with an anthracycline, a taxane, and capecitabine (BEACON): a randomised, open-label, multicentre, phase 3 trial. Lancet Oncol. 2015 Nov;16(15):155668.

19 Cortés J, Lipatov O, Im SA, Goncalves A, Lee KS, Schmid P, et al. KEYNOTE-119: phase III study of pembrolizumab (pembro) versus single-agent chemotherapy (chemo) for metastatic triple negative breast cancer (mTNBC) [Abstract]. Ann Oncol. 2019 Oct;30(suppl 5): v859.

20 Xi J, Oza A, Thomas S, Ademuyiwa F, Weilbaecher K, Suresh R, et al. Retrospective analysis of treatment patterns and effectiveness of palbociclib and subsequent regimens in metastatic breast cancer. J Natl Compr Canc Netw. 2019 Feb;17(2):141-7.
21 Schmid P, Adams S, Rugo HS, Schneeweiss A, Barrios $\mathrm{CH}$, Iwata $\mathrm{H}$, et al. Atezolizumab and nab-paclitaxel in advanced triple-negative breast cancer. N Engl J Med. 2018 Nov; 379(22):2108-21.

22 Gao JJ, Cheng J, Bloomquist E, Sanchez J, Wedam SB, Singh H, et al. CDK4/6 inhibitor treatment for patients with hormone receptor-positive, HER2-negative, advanced or metastatic breast cancer: a US Food and Drug Administration pooled analysis. Lancet Oncol. 2020 Feb;21(2):250-60.

23 Krop IE, Kim SB, Martin AG, LoRusso PM, Ferrero JM, Badovinac-Crnjevic T, et al. Trastuzumab emtansine versus treatment of physician's choice in patients with previously treated HER2-positive metastatic breast cancer (TH3RESA): final overall survival results from a randomised open-label phase 3 trial. Lancet Oncol. 2017 Jun;18(6):743-54.

24 Dieras V, Miles D, Verma S, Pegram M, Welslau M, Baselga J, et al. Trastuzumab emtansine versus capecitabine plus lapatinib in patients with previously treated HER2-positive advanced breast cancer (EMILIA): a descriptive analysis of final overall survival results from a randomised, open-label, phase 3 trial. Lancet Oncol. 2017 Jun; 18(6):732-42.

25 von Minckwitz G, Huang CS, Mano MS, Loibl S, Mamounas EP, Untch M, et al. Trastuzumab emtansine for residual invasive HER2positive breast cancer. N Engl J Med. 2019 Feb;380(7):617-28.

26 Bonotto M, Gerratana L, Iacono D, Minisini AM, Rihawi K, Fasola G, et al. Treatment of metastatic breast cancer in a real-world scenario: is progression-free survival with first line predictive of benefit from second and later lines?. Oncologist. 2015 Jul;20(7):719-24.

27 Park IH, Lee KS, Ro J. Effects of second and subsequent lines of chemotherapy for metastatic breast cancer. Clin Breast Cancer. 2015 Feb;15(1):e55-62.
28 Chung CT, Carlson RW. Goals and objectives in the management of metastatic breast cancer. Oncologist. 2003;8(6):514-20.

29 Carrick S, Parker S, Thornton CE, Ghersi D, Simes J, Wilcken N. Single agent versus combination chemotherapy for metastatic breast cancer. Cochrane Database Syst Rev. 2009 Apr;2009(2):CD003372.

30 Dear RF, McGeechan K, Jenkins MC, Barratt A, Tattersall MH, Wilcken N. Combination versus sequential single agent chemotherapy for metastatic breast cancer. Cochrane Database Syst Rev. 2013 Dec;2013(12):CD008792.

31 Suzuki C, Blomqvist L, Hatschek T, Carlsson L, Einbeigi Z, Linderholm B, et al. Impact of the first tumor response at eight weeks on overall survival in metastatic breast cancer patients treated with first-line combination chemotherapy. Med Oncol. 2013 Mar;30(1):415.

32 Bruzzi P, Del Mastro L, Sormani MP, Bastholt L, Danova M, Focan C, et al. Objective response to chemotherapy as a potential surrogate end point of survival in metastatic breast cancer patients. J Clin Oncol. 2005 Aug; 23(22):5117-25.

33 Hackshaw A, Knight A, Barrett-Lee P, Leonard R. Surrogate markers and survival in women receiving first-line combination anthracycline chemotherapy for advanced breast cancer. Br J Cancer. 2005 Nov;93(11): 1215-21.

34 Burzykowski T, Buyse M, Piccart-Gebhart MJ, Sledge G, Carmichael J, Lück HJ, et al. Evaluation of tumor response, disease control, progression-free survival, and time to progression as potential surrogate end points in metastatic breast cancer. J Clin Oncol. 2008 Apr;26(12):1987-92.

35 Hayes DF, Cristofanilli M, Budd GT, Ellis MJ, Stopeck A, Miller MC, et al. Circulating tumor cells at each follow-up time point during therapy of metastatic breast cancer patients predict progression-free and overall survival. Clin Cancer Res. 2006 Jul;12(14 Pt 1):421824. 